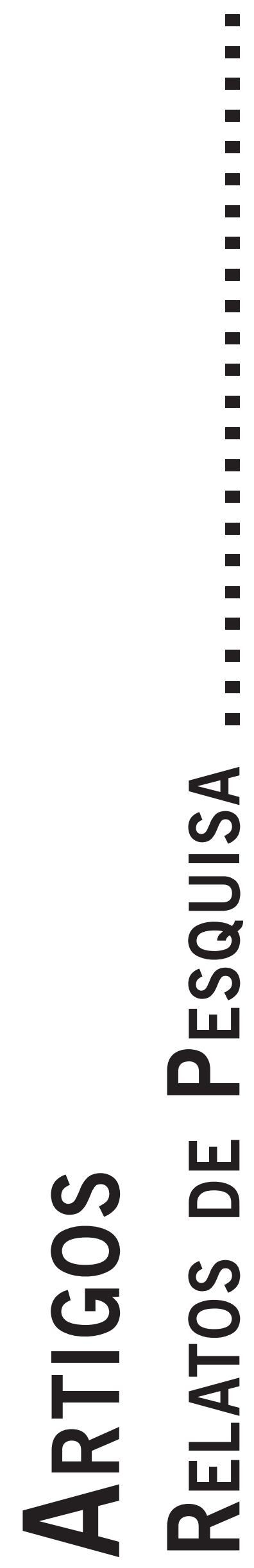




\title{
O SENTIDO DE SER PROFESSOR DA LÍNGUA PORTUGUESA EM ESCOLA PÚBLICA: UMA PESQUISA FENOMENOLÓGICA
}

\author{
The Meaning of Being a Portuguese Language Teacher in a Public School: \\ a Phenomenological Research \\ El Sentido de Ser Profesor de la Lengua Portuguesa en Escuela Pública: \\ Una Investigación Fenomenológica
}

\author{
Sandra Souza da Silva \\ Francisco Bento da Silva Filho \\ Noely Cavalcanti de Menezes \\ Bruna Jucilene Carlos Gonzaga \\ Cicera Michelly de Sousa Teles
}

\begin{abstract}
Resumo: A Modernidade sinaliza o momento histórico em que a escola assume o formato atual, com expectativas em face da atuação dos professores. Estes têm sido alvo de diversos estudos, detectando-se com frequência processos de adoecimento, exposição à violência e desvalorização da profissão; quadro agravado no âmbito da escola pública. Considerando o ensino da língua portuguesa como central na formação dos estudantes, conforme rezam as diretrizes da Lei 9394/1996 (LDB) e os Parâmetros Curriculares Nacionais (PCN), questiona-se qual o sentido de ser professor em escola pública. Participaram da pesquisa seis professores de Língua Portuguesa do ensino médio de uma escola estadual na cidade de João Pessoa - PB, sendo cinco do sexo feminino. Foi utilizado o método Versão de Sentido (VS), com a pergunta-estímulo: “Que sentido teve esta aula para mim?”, respondida por cada professor ao final de oito aulas, totalizando 48 VS. Identificaram-se 16 eixos de sentido, distribuídos em dois grupos. Um com foco no contexto relacional, e outro no modelo político-social e atividade docente. Observaram-se tanto aspectos positivos quanto negativos, permeando os eixos de análise, como, satisfação com o magistério, preocupação com a formação discente e insatisfação com a política educacional.
\end{abstract}

Palavras-chave: Professor; Escola pública; Fenomenologia.

\begin{abstract}
Modern age points out the historical moment in which School assumes the current configuration, regarding expectations of teachers' performances. These have been the aim of several researches, frequently detecting sickening processes, exposition to violence and depreciation of the profession, worsened when it comes to Public Schools' sphere. Considering the Portuguese language teaching central to students' formation, according to the guidelines of Law 9394/1996 (LDB) and the National Education Parameters (PCN), it wonders the meaning of being a teacher in a Public School. Six Portuguese language teachers of a Public School in João Pessoa took part in the research; five of them were female. The method picked was the sense's versions (SV), using the question-stimulus: "What was the meaning of this class to me?", answered by each teacher at the end of eight classes, totaling $48 \mathrm{SV}$. Sixteen axes direction were identified, divided in two groups. The first one focusing the relational context and the other one focusing the political-social structure and docent activity. Both positive and negative aspects were noticed permeating the analysis axis such as satisfaction with the profession, concerns with the students' formation and dissatisfaction with the educational policies.
\end{abstract}

Keywords: Teacher; Public school; Phenomenology.

Resumen: La modernidad señala el momento histórico en que la escuela asume la forma atual, con expectativa alrededor de los profesores. Eses tienen sido foco de diversos estudios, detectando com frecuencia procesos de contracción de enfermidad, exposición a la violencia y desvalorización de la profesión; cuadro agravado al ámbito de la escuela pública. Considerando la enseñanza de la lengua portuguesa como centro en la formación de los estudiantes, según las directrizes de la ley 9394/1996 e los parámetros curriculares nacionales, cuestiona cual es el sentido de ser profesor en la escuela pública. Participaron de la investigación seis profesores de la lengua portuguesa de la enseñanza secundaria de una escuela estatal en la ciudad de João Pessoa - PB, siendo cinco del sexo femenino. Fue utilizado el método versión del sentido, con la pregunta-estímulo: “ ¿Qué sentido tuvo esa clase para mi?”, contestada por cada profesor al final de 8 clases, con un total de 48 VS. Identificaron 16 ejes de sentido, distribuídos en dos grupos. Uno con eje en lo contexto relacional, y outro en el molde político social y atividad docente. Observaron aspectos positivos cuanto negativos, en los ejes de análisis, como, satisfacción con el magisterio, preocupación con la formación de alumnos e insatisfacción con la política educacional.

Palabras-clave: Profesor; Escuela pública; Fenomenología. 


\section{Introdução}

$\mathrm{O}$ alvorecer da escola, no formato que lhe emprestou a Modernidade, data do século XV; inicialmente, grupos da população eram selecionados, segundo suas capacidades e colocados sob a batuta de um mestre, num local comum a vários grupos. Já no século XVI, as classes e seus mestres foram isolados em espaços físicos separados. Essa alteração, de inspiração parisiense e flamenga, configura os primórdios da estrutura que conhecemos como classes escolares (Ariés, 1981). Daquele momento histórico até hoje, considerando os inúmeros arranjos civilizatórios e culturais, a concepção do ser professor também foi reconfigurada, novas atribuições e expectativas lhes foram ensejadas, não obstante o fio condutor que harmoniza esse percurso: o trabalho com pessoas, a preocupação com a formação humana e profissional; atentando à convocação do modelo societário vigente ou à sua revelia.

No presente, com as metamorfoses do mundo do trabalho, outras exigências e desafios se associam ao labor docente. Em alguns contextos, a precarização das condições de trabalho, o processo de sucateamento da escola pública, as críticas condições sociais da clientela, o baixo prestígio social da profissão, salários aviltantes e o avanço do saber nas sociedades pós-industriais (que determina a necessidade de atualização contínua, renúncia a conteúdos seculares, além da possibilidade de o professor ser confrontado/questionado), têm gerado tensões e um clima laboral desfavorável ao exercício da prática docente. Um recorte especial pode-se fazer quanto às novas demandas associadas ao labor docente: a assunção de responsabilidades originalmente assumidas pelas famílias, como o diálogo em torno dos valores, quer seja pelas condições sociais adversas daquelas, quer seja pela substituição vertiginosa dos valores que harmonizavam até então as relações sociais, marca do tempo presente.

Em síntese, a atividade docente é transpassada por diversos estressores que variam em níveis de influência: os de natureza psicossocial (relacionados à função docente em si), os presentes no ambiente laboral (aqui inclusas condições de trabalho, concorrência, novas exigências acadêmicas) e os inerentes ao modelo socioeconômico e político (os ligados à precarização e desvalorização da escola pública e da profissão docente) (Carlotto, 2002, Oliveira, 2004).

\section{Esquadrinhando o contexto}

A reestruturação produtiva vem tendo impacto no cenário social, nas últimas décadas e acarretando, com isso, mudanças nas formas de gestão e organização do trabalho escolar, interferindo na dinâmica do trabalho do professor como intensificação e ampliação do raio de ação, ocasionando o tão comentado desgaste. No que se refere à rede pública de ensino, o fato se agrava quando se observa o aumento dos contratos temporários, o arrocho salarial, possíveis inadequações de planos de cargos e salários, trazendo muitas vezes instabilidade do emprego no ensino público (Oliveira, 2004).

O quadro até aqui delineado tem suscitado pesquisas nacionais e internacionais, as quais têm apontado alguns achados sobre o estresse da categoria. Gomes, Montenegro, Peixoto \& Peixoto (2010) avaliaram indicadores relacionados com o trabalho e o bem-estar pessoal (estresse, burnout, saúde física e satisfação profissional) de professores do ensino secundário da zona norte de Portugal. O estudo mostrou que a fonte de elevado nível de estresse dos docentes está relacionada primeiramente com os alunos, devido ao mau comportamento em sala de aula, falta de interesse e motivação diante da aprendizagem e da escola. Outras fontes de estresses dizem respeito à falta de medidas disciplinares para atuar nestas situações e às políticas disciplinares inapropriadas da escola e do ensino. Estes fatores provocam o esgotamento profissional, além de apresentarem problemas de exaustão emocional, despersonalização e baixa realização profissional. Outro estudo realizado por Gomes, Silva, Mourisco, Silva, Mota \& Montenegro (2006) mostrou que a insatisfação do professor com a atividade docente está relacionada com os comportamentos de indisciplina dos alunos, o trabalho burocrático e excesso de aulas, redundando em exaustão emocional e comprometimento da saúde física.

Na realidade paraibana, especificamente na cidade de João Pessoa, Mariano e Muniz (2006), ao fazerem uma pesquisa com professores da rede pública municipal, identificaram a situação de trabalho vinculada à saúde mental das professoras da $2^{\text {a }}$ fase do Ensino Fundamental e verificaram que o exercício da profissão docente é constituído de fatores que comprometem a saúde física e mental das professoras. As queixas mais frequentes observadas nesta pesquisa foram: desvalorização do magistério, o que pode ser observada no salário insuficiente às suas necessidades; descrença quanto à melhoria nas condições de trabalho; sobrecarga de trabalho com necessidade de realizar múltiplas tarefas ao mesmo tempo, como, dar aula, correção de provas, planejamento, trabalho levado para casa, etc.

Em período mais recente e na mesma cidade, Batista, Carlotto, Coutinho \& Augusto (2010), ao investigarem sobre a Síndrome de Burnout e sua relação com fatores sociodemográficos e laborais também em professores de escolas municipais, verificaram que a amostra apresentou 8,3\% de alto nível de Despersonalização, 33,6\% de alto nível de Exaustão Emocional e 56,6\% de alto nível de Baixa Realização Pessoal no trabalho, configurando-se assim em um conjunto de sinais e sintomas, que podem repercutir em na saúde mental do docente, mesmo que não se transforme em transtornos mentais graves. 
Somando-se a isso, foi possível ainda observar que o distanciamento e o endurecimento afetivo no trabalho estavam associados a pessoas que não tinham companheiro fixo, com mais de 40 anos, estáveis no emprego e com mais de 20 anos na profissão. Observou-se ainda que o esgotamento de recursos emocionais com relação ao trabalho apresentou relação com carga máxima de trabalho; sentimento de que a vida pessoal é atingida pelo trabalho e também já pensaram em mudar de profissão, por seu alto grau de estresse. A baixa Realização Profissional estava relacionada a professores com filhos e com elevada carga horária de trabalho, e que sentiam que a profissão está interferindo na vida pessoal deles, além de considerarem a profissão menos interessante do que quando começaram a trabalhar.

De um lado, é crescente a demanda de queixas e conflitos relacionados ao trabalho docente. Por outro, o espaço da escola, apesar de muitas vezes comprometer a saúde do trabalhador, também pode ser um local de crescimento, qualidade de vida, sentido e realização profissional. Pergunta-se, então: que sentido o ambiente escolar público tem para o professor? Basso (1998), firmado numa perspectiva histórico-social, afirma que a ruptura entre significado e sentido torna o trabalho alienado, comprometendo a atividade docente.

No contexto brasileiro, é cediço o embate de forças, presente na elaboração e edição dos textos legais, os quais normatizaram o caminhar do ensino público, tendo em conta todas as demandas acima frisadas e a obrigatoriedade de dar cumprimento ao estabelecido na Constituição Federal de 1988 e na Lei de Diretrizes e Bases da Educação Nacional (LDB). Os Parâmetros Curriculares Nacionais (PCN) representam o documento que objetiva nortear as discussões curriculares, juntamente com Estados e Municípios, integrando a proposta didática do ensino da língua materna e demais componentes curriculares.

\section{O Ensino da língua portuguesa}

Os PCN do ensino médio, que tratam da área de linguagens, códigos e suas tecnologias, especificam o ensino da Língua Portuguesa, que, dentre outros, deverá propiciar ao aluno a possibilidade de "compreender e usar a Língua Portuguesa como língua materna, geradora de significação e integradora da organização do mundo e da própria identidade" (Brasil, 2000, p. 14). O documento referencia, complementando, as determinações contidas na LDB e no Parecer 15/98, do Conselho Nacional de Educação - Câmara Educação Básica. Frutos de longo e sinuoso caminho, inaugurado com o processo de redemocratização do país, os PCN sinalizam para a diversidade como norte e registram a necessidade de que os Estados e Municípios contextualizem as competências e habilidades sugeridas às suas especificidades.
É inegável, considerando as inúmeras transformações por que passou ao longo da história e dos textos legais que a disciplinaram, que a Língua Portuguesa revela-se como importante instrumento de leitura e comunicação com o mundo, num processo de interação social entre as pessoas, construindo significados pessoais e grupais. Importa ressaltar o caráter transdisciplinar da mesma, vez que ela é base para todos os outros saberes. A utilização da língua, em suas diversas formas, expressa desejos, visões de mundo, saberes, valores, paixões e pontos de vista. A ideia concernente ao estudo da Língua Portuguesa, considerando a complexidade humana, é de um uso estético e ético, que viabilize o trânsito no espaço social e a capacidade de transformá-lo. Outro aspecto a ser considerado é a possibilidade de produção artística, pessoal, criativa, que pode tipificar quem o produz, realçando sua dimensão dialógica.

Destacando a importância do ensino da língua pátria, referenciada nas linhas anteriores, intenta-se carrear mais elementos à discussão, objetivando a presente pesquisa, sob um recorte fenomenológico, apreender a experiência de ser professor da Língua Portuguesa, de uma escola pública da cidade de João Pessoa - PB.

\section{Percurso metodológico}

Trata-se de uma abordagem descritiva, cuja ideia principal é de deixar que o fenômeno fale por si mesmo, na tentativa de se alcançar ao máximo a sua totalidade. Busca-se acessar o sentido da experiência para as pessoas que a vivenciaram e que estão aptas a descreverem de modo compreensivo (Holanda, 2006). Segundo Amatuzzi (2009), na psicologia fenomenológica, quando se refere a um saber científico concebido em uma direção qualitativa, o pesquisador recolhe informações de modo sistemático "entrando em alguma situação previamente escolhida ou de alguma forma planejada" (p. 97).

\section{Participantes}

Participaram da pesquisa seis professores de Língua Portuguesa do ensino médio de uma escola estadual na cidade de João Pessoa, Paraíba, sendo cinco do sexo feminino. A idade variou entre 30 e 50 anos. No que se refere ao estado civil, três professores são solteiros e três são casados; três são católicos e três são evangélicos. Em relação à renda mensal, quatro possuem renda entre três a cinco salários mínimos, trabalhando na sua maioria dois turnos. Os demais possuem uma renda acima de seis salários mínimos, trabalhando durante dois e três turnos. O tempo de serviço dos professores em escola pública varia entre quatro e 28 anos. 


\section{Instrumento}

Para acessar o vivido do professor foi utilizado o método Versão de Sentido - VS (Amatuzzi, 2009). A seguinte pergunta serviu como estímulo para os (as) professores (as) entrarem em contato com o significado da aula ministrada: "Que sentido teve esta aula para mim?". O sentido de cada professor (a) foi registrado por eles em um caderno individual, cedido pelos pesquisadores. Sob o suporte da Fenomenologia, a VS configura-se como um procedimento metodológico, que consiste na expressão autêntica, sincera, vivencial da fala de uma pessoa, solicitada logo após a realização de determinada atividade. Importa destacar, em específico, que a VS encontra supedâneo teórico na Fenomenologia da Linguagem, com os pensamentos de Martin Buber e Merleau-Ponty e pode ser utilizada em atendimentos terapêuticos, práticas educativas e docentes, atividades de formação, supervisão, bem assim em pesquisas científicas (Vercelli, 2006).

\section{Procedimento para acessar a experiência dos pro- fessores}

Tendo a aceitação da realização do projeto pela direção da escola, a equipe de pesquisadores entrou em contato com os professores da língua portuguesa para apresentar o projeto e averiguar quem gostaria de fazer parte da pesquisa, totalizando os seis primeiros que se disponibilizaram, sendo este o critério de inclusão da amostra.

O projeto foi apresentado aos professores em uma reunião e a participação voluntária foi consentida. Nesta reunião foram agendados os dias de coleta das VS, de acordo com a disponibilidade de cada um. Imediatamente após o término da aula, o professor escrevia a resposta para a pergunta estímulo em um ca- derno individual, o qual ficava com o pesquisador responsável, que assegurava para o participante o sigilo de seu relato. O processo de escrita das VS aconteceu para cada professor em uma aula por semana durante oito encontros, totalizando deste modo dois meses de registro dos relatos. Ao final foram contabilizadas oito VS para cada professor. Responderam ainda uma ficha sócio-demográfica contendo informações como sexo, estado civil, tempo de profissão, renda, turnos de trabalho, condições de trabalho, etc.

\section{Procedimento para análise dos relatos}

Foram feitas análises das VS, através de uma leitura minuciosa, a fim de encontrar os eixos significativos, que possibilitassem uma compreensão sobre o sentido de ser professor. Intentou-se uma articulação desses eixos em um texto consistente e unificado, para a construção de uma interpretação mais ampla do fenômeno, elaborando assim uma compreensão além das situações particulares (Amatuzzi, 2009).

\section{Resultados e discussão}

Foram extraídos 16 eixos das 48 VS analisadas, organizando-os em dois grandes grupos representativos. Um que trata de eixos que têm como foco o contexto relacional entre professor e aluno, escola e família e também a relação entre pesquisadora e participante da pesquisa, com nove eixos. No outro grupo, encontram-se sete eixos que tratam do modelo político-social e da atividade docente em si, representados por condições de trabalho, política educacional, realização com a atividade docente, metodologia de ensino e percepção de desvalorização do trabalho docente, todos reunidos na Tabela 1.

Tabela 1: Agrupamento dos eixos de sentido

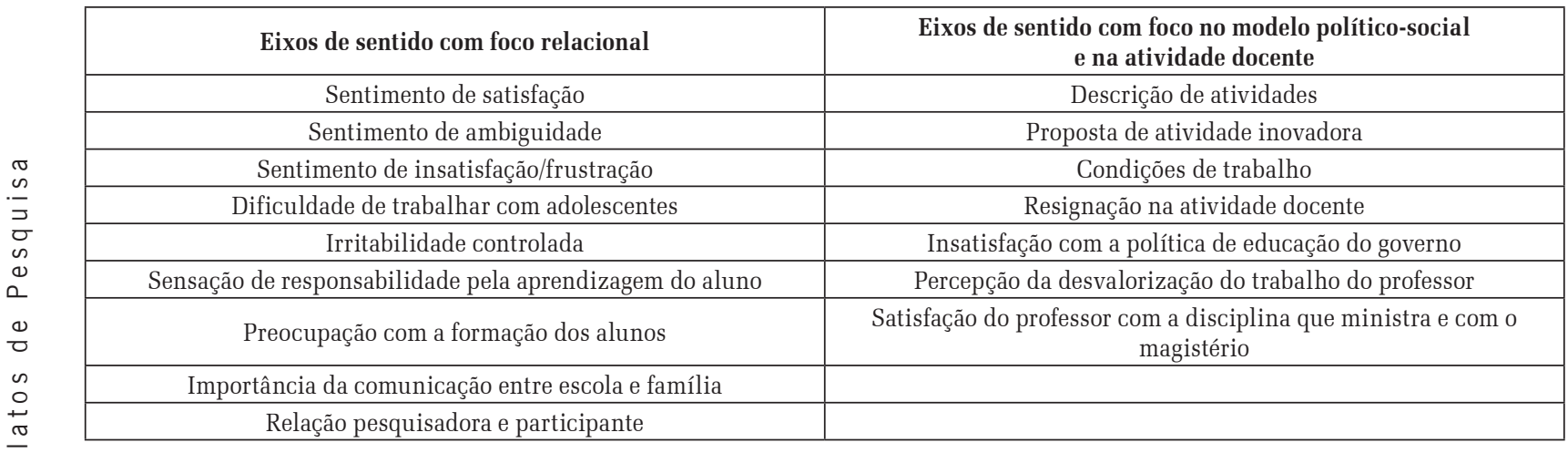


A seguir será discutido cada grupo dos eixos a começar com os centrados no foco relacional.

\section{Eixos de sentido com foco relacional}

Agruparam-se no primeiro eixo (sentimento de satisfação do professor) as VS dos professores que sinalizam para a satisfação que o professor sente quando percebe que os alunos participam ativamente das aulas, que os objetivos são atingidos e também quando os alunos demonstram interesse pelo conteúdo trabalhado.

Hoje a aula apresentou muito sentido, consegui fazer o que pretendia. Não é sempre que consigo ministrar um conteúdo e o mesmo ficar legal, bem trabalhado e concretizado na cabeça do aluno. Acho que é a turma que colabora e participa da aula. Sinto-me muito bem quando o conteúdo flui, assim vejo que o sentido foi alcançado. (P1)

Ao longo das VS, foi possível perceber o quanto é gratificante para o professor essa relação de troca em sala de aula, quando os alunos se dispõem a participar. Importa também assinalar que utilizar temas que sejam de interesse dos alunos parece ter um diferencial na participação dos mesmos. Por isso resta essencial inovar em sala de aula, seja com temas que despertem o interesse ou simplesmente com metodologias que despertem a atenção dos alunos, como é possível ver no relato seguinte: "Estamos trabalhando concordância nominal e esse assunto chama a atenção dos alunos e para mim isso é muito importante. Diante desse aspecto da aula, sinto-me bastante motivado, sendo assim, o sentido da aula foi maravilhoso". (P1)

Das falas precedentes realça-se a perspectiva da educação enquanto atividade peculiarmente humana e que extrapola o aspecto cognitivo, trazendo a lume o componente sensível, envolvendo o humano, o emocional, o subjetivo, presentificados na experiência. Discernindo a educação tradicional da aprendizagem significativa, Macêdo (2000) destaca que na primeira, o foco é o desenvolvimento da inteligência e da consciência cognitiva, enquanto que na segunda, o centro reside no crescimento total do indivíduo, envolvendo não só o componente cognitivo, mas também a percepção, a afetividade, a emoção, afirmadas no encontro entre educador e educando.

Também se encontram relatos que se referem à satisfação do professor em realizar sua atividade, porém com um sentimento carregado de ambiguidade, que foram colocados no eixo sobre o sentimento de ambiguidade/satisfação pelo conteúdo ministrado x insatisfação pela assimilação parcial do conteúdo pelos alunos, experienciado na atividade docente. Neste caso, o professor se sente, por um lado satisfeito e, por outro, com um sentimento desconfortável, uma vez que se encontra consciente da assimilação apenas em parte do conteúdo previsto e apenas por alguns alunos, o que parece comum em uma turma heterogênea e, muitas vezes, com número demasiado de alunos. A esse respeito, não temos uma legislação federal ou estadual que discipline a matéria. Em geral, os Conselhos estaduais e municipais de Educação, através dos sensos escolares determinam o número máximo de alunos por sala através de edição de portaria. O que se tem em nível federal é um Projeto de Lei iniciado no Senado - PLS, da lavra do Senador pernambucano Humberto Costa que altera a Lei 9394/1996 (LDB), estabelecendo o número máximo de 25 (vinte e cinco) alunos por turma na pré-escola e 30 (trinta) alunos por turma no ensino fundamental e médio. O PLS em tela encontra-se na Câmara Federal dos Deputados para apreciação.

Hoje posso dizer que a aula transcorreu com tranquilidade, o que me deixou feliz, pois um percentual grande da turma não só respondeu exercícios propostos como participou ativamente da aula. (...) De qualquer modo, eu não dei a aula sozinha. Houve interação e no contexto de sala de aula, isso é sempre bom. Vale lembrar que essa interação não se deu com 100\% da turma. Percebi alguns (poucos) alunos desestimulados, desinteressados e, apesar de eu lhes chamar a atenção, permaneceram alheios. Esse comportamento, embora seja incômodo, é corriqueiro, nas escolas públicas especialmente (...). (P2).

A ênfase à escola pública acentuada neste último relato deixa patente que o comportamento alheio dos alunos é uma especificidade daquela, segundo o pesquisado. Pode-se ler o comentário a partir da teoria do capital cultural na escola. Nogueira \& Nogueira (2002) assinalam que para Bourdieu cada aluno herda uma bagagem social composta de elementos materiais, o capital econômico e elementos subjetivos, o capital cultural. Por este entenda-se o conjunto das influências sociais da família, seus títulos escolares e acesso à cultura erudita. Essa circunstância promove no escolar a incorporação desses elementos à sua subjetividade, determinando maior probabilidade de sucesso na escola.

O contraponto dos eixos anteriores, sentimento de insatisfação/frustração, também se fez presente nas VS dos professores, as quais parecem apontar que a insatisfação e frustração que o professor sente em sala de aula estão relacionadas com o desinteresse e não dedicação dos alunos, interesse dos alunos condicionado às questões da prova, desesperança na relação professor-aluno, percepção da desmotivação dos alunos em relação à aula. Este eixo mostra a necessidade que o professor tem de que os alunos participem do processo de aprendizagem, configurando-se como uma verdadeira troca. 
(...) Eles só se preocupam com notas, mas só depois da prova para saber se foram bem ou não, porém em relação ao aprendizado não estão nem aí, o que importa é passar. Hoje estou um pouco cansada, louca pelo dia de amanhã, será minha folga. (...) O restante do horário que foi nas turmas J e H, me deram a sensação que estamos em um palco, eu represento a professora que acredita na boa vontade do aluno para aprender e os alunos representam com muita propriedade que não estão nem aí para aula alguma. (P4)

Segundo Carlloto, 2002, a relação professor-aluno influencia no bem-estar do primeiro, na sua carreira e na aprendizagem dos alunos. Neste sentido pode-se dizer que quando o professor não tem boa relação com o aluno, gera um sentimento de insatisfação e frustração, que influencia a sua saúde emocional, seu trabalho e a aprendizagem, o que ficou bastante presente nos relatos anteriores.

A dificuldade de trabalhar com adolescentes, é para o professor um aspecto negativo devido à dificuldade de estabelecer ordem. Questionamos se essa faixa etária contribui de modo significativo para o cansaço e esgotamento do professor em sala de aula, pela própria especificidade da adolescência, como resta explícito na fala seguinte:

Um aspecto negativo na aula, e considero que seja característica dos debates, é que às vezes os envolvidos não sabem ceder à fala ao outro. Então, considerando o tema e o público da aula (adolescentes) fica difícil estabelecer a ordem. (P2)

A dificuldade que o professor sente em trabalhar com a faixa etária em questão, parece indicar o eixo a seguir, como sendo fruto de uma relação difícil com adolescentes, uma vez que foram encontradas falas que expressam a necessidade de habilidades para além do domínio do conteúdo e de práticas de ensino. $\mathrm{O}$ eixo irritabilidade controlada faz referência à significativa necessidade de autocontrole e conhecimento de seus limites por parte do professor, por exemplo, para o estabelecimento de um clima favorável à aprendizagem.

Para Carlotto (2002), assumir as novas funções que o contexto escolar exige, supõe um domínio que ultrapassa a acumulação de conhecimentos. São exigidas habilidades pessoais que permitam superar os múltiplos estressores daquele ambiente e responder as expectativas. $\mathrm{O}$ professor se depara, nesse processo, com a necessidade de desempenhar diversos papéis, muitas vezes contraditórios, que lhe exige manter o equilíbrio emocional constantemente: “(...) Em certos momentos manter o controle e não agredir/revidar verbalmente chega a ser um ato de extremo sacrifício (...)” (P5).

As análises das VS mostraram que os professores sentem-se responsáveis pela aprendizagem do aluno, desenvolvendo uma culpa por não prender-lhes a atenção e sentindo-se impotentes. A culpa aqui desenvolvida decorre do modelo tradicional de ensino em que o professor é o responsável em depositar no aluno o conteúdo programático. A esse respeito Freire (1996) erige crítica à educação tradicional que cunhou de educação bancária; que, em termos sintéticos, informa as práticas pedagógicas tradicionais, nas quais o professor "deposita” as informações nas mentes dos educandos, que as devolvem em etapa posterior, isentas de reprocessamento. Nessa perspectiva, professor e aluno são espécies de tubos estéreis, onde passa o conhecimento alienado e alienante. Mais do que isso, a culpa parece sobrecarregar o professor em sua atividade docente, fazendo-o perceber-se como o único responsável pelo seu trabalho e adoecimento, eliminando quaisquer outras variáveis que possam interferir nesse processo, como, as condições e processos de trabalho. Essa discussão é abordada no estudo das clínicas do trabalho, compreendendo um conjunto de teorias que foca a relação entre trabalho e subjetividade e intenta um olhar aguçado "às diversas modalidades de manifestação do mal-estar no trabalho, incluindo doenças físicas, transtornos e alterações mentais e psicossociais" (Bendassolli \& Sobol, 2011, p.15).

É o que observamos a seguir: "(...) A sensação é de fracasso total porque eu fico me perguntando o que fazer para estimular esses alunos. A realidade da sala de aula está cada vez mais difícil. Eu quero pedir “socorro”'. (P2); “(...) Preciso pensar um meio de prender a atenção deles quando trabalho fábulas. Ao final da aula senti insatisfação com eles e também comigo. (P5)”. Na preocupação com a formação dos alunos enquadram-se comentários que expressam um real incômodo e descontentamento dos professores acerca da realidade que vivenciam, assim como um sentimento de preocupação com o porvir acadêmico dos alunos.

(...) Muitas vezes chego a compreender a vontade deles de fugirem ao lembrar que minha época de estudante do ensino médio, fazia a mesma coisa que eles. Então, nesse tipo de caso não chego a me sentir péssima, porque a reação deles seria igual com qualquer outro professor que tivesse a última aula numa sexta-feira. (...) Ao final das aulas, muitas vezes me pergunto como será o futuro desses jovens (P4).

A aula não foi muito significativa. Esse modelo de ensino que figura nas escolas públicas do Brasil não acrescenta muito aos nossos alunos. (...) Diante disso, a sensação que fica é a de fracasso. Porque eu fico me perguntando o que foi que acrescentei para o meu aluno hoje, e a minha resposta é: Quase nada! (P2).

A partir dos relatos pertencentes ao eixo Importância da comunicação entre escola e família, pode-se notar uma valorização, necessidade e satisfação, por parte do professor, em relação à manutenção de contato entre pais e escola. 
No que se refere ao contato docente e comunidade, Oliveira (2004) aponta, entre outros, para a importância e benefício dessa articulação, por exemplo, na elaboração e decisão das políticas públicas e do Projeto Político Pedagógico. Esse contato permite um maior conhecimento das possíveis causas geradoras de dificuldades, assim como soluções que possam levar a um maior benefício da comunidade escolar, o que pode ser observado no relato a seguir: "Hoje na última aula foi tranquilo, pois ontem teve reunião com os pais e os alunos estavam bem calmos e fazendo as atividades" (P3).

A relação pesquisadora e participante foi um importante indicativo nesta pesquisa de caráter qualitativo. Em torno desse fato Feijoo \& Magnan (2012) assinalam que a postura do pesquisador pautado nas premissas fenomenológicas existenciais é a de preocupação com o universo e sujeitos pesquisados e não só de ocupação. Esta revelaria apenas uma utilidade instrumental, enquanto que a preocupação desenvolve a autonomia e o poder decisório do pesquisado:

Bom, hoje é o último dia de recolhimento de sentimentos, besteiras, desabafos, alegrias, e espero ter demonstrado mais que tudo, muito prazer na realização das minhas atividades como professora. E tudo de bom para você moça observadora. Abraços. Precisando, sempre as ordens (P5).

\section{Eixos de sentido com foco no modelo político-social e na atividade docente}

Através das análises das VS foi possível perceber relatos objetivos, neutros e descritivos a respeito do vivido. Segundo Amatuzzi (2009) é comum que isso ocorra, pois a VS é algo que se aprende a fazer à medida que se pratica, até chegar a uma fala autêntica resultante da experiência imediata. Por esse motivo, a descrição objetiva do ocorrido se fez presente especialmente no início da pesquisa e dos relatos, o que podemos observar no eixo descrição de atividades: "Despertar o interesse dos alunos pela nossa literatura através da obra de José de Alencar. Para atingir o objetivo, foi feito um seminário aonde os alunos vêm aos poucos se inteirando ao conteúdo estudado". (P6)

A proposta de atividade inovadora refere-se à necessidade do professor de usar a criatividade para propor novas atividades que motivem e envolvam os alunos na aula como também é uma proposta de alternativa ao modelo de ensino tradicional, que é caracterizado por aulas expositivas, nas quais o professor dá o conteúdo, sem a interação e participação dos alunos, tornando as aulas cansativas e desmotivadoras para ambos, como percebido na fala seguinte: “(...) Uma aula de língua portuguesa (gramática) na qual o professor expõe o conteúdo e o aluno apenas ouve, sem nenhuma participação não acres- centa muito. Aliás, desmotiva a todos. Não só desmotiva como também cansa" (P2). De igual modo, o relato a seguir dimensiona a mesma preocupação:

Para atingir o objetivo, foi feito um seminário onde os alunos vêm aos poucos se inteirando ao conteúdo estudado. Está valendo a pena, pois têm surgido novidades fora dos livros e eles estão se utilizando das novas tecnologias para apresentar seus trabalhos. A minoria está fazendo um trabalho comum. (P6).

Para Basso (1998), as mudanças nas práticas pedagógicas são influenciadas pelas condições subjetivas do professor, que envolve sua formação e sua compreensão do significado do seu trabalho. Para tanto, a criatividade parece ser fundamental no desempenho da atividade docente, colaborando na busca de solução do fracasso escolar, na construção de projetos, na execução de programas para melhorar o desempenho dos alunos e nas relações interpessoais.

No que se refere às condições de trabalho, assunto tão discutido na literatura (Frigotto, 2000; Carlotto, 2002; Silva 2010), encontram-se relatos que se referem a um claro desgaste físico e psíquico dos professores, relacionado às diversas dificuldades enfrentadas por esses profissionais em seu cotidiano escolar. Por diversas vezes, queixas relacionadas à falta de interesse do aluno e a falta de valorização da categoria, por exemplo, mostraram-se um importante indicativo de insatisfação e de desmotivação com a profissão.

Carlotto (2002) faz referência aos diversos estressores presentes no contexto docente. Para ela, esses estressores estão relacionados a diversos motivos, entre eles: a natureza de suas funções, ao contexto institucional e social onde estão inseridos. Fala-se ainda, na tendência à Síndrome de Burnout, caso esses estressores sejam mantidos. Há a identificação, dentre outros sintomas, da perda de entusiasmo e de criatividade, de tendência a fácil frustração, assim como desmotivação e falta de perspectiva de mudança: "Exaustão absoluta apesar do assunto ter sido dado nas primeiras aulas com muito entusiasmo. $\mathrm{O}$ barulho e a falta de interesse interferem diretamente no meu entusiasmo. Liberei dez minutos, pois estava sem voz" (P6); e ainda: "Minha última aula foi cansativa e desanimada. Precisei chamar a atenção dos alunos o tempo todo e com aquela sensação de que ninguém quer nada com nada" (P4).

Quanto à resignação na atividade docência, pode-se dizer que é consequência das condições de trabalho vivenciadas pelos professores, representada no eixo anteriormente discutido. Caracteriza-se por falas que expressam desestímulo ao exercício da profissão, aliado ao conformismo e a falta de perspectivas de mudança do contexto vivenciado. 
As duas últimas aulas. Numa sexta-feira. Não é fácil para ninguém: Nem alunos e nem professor. Mas a aula tem que acontecer. Muitas vezes, dependendo do ânimo (ou desânimo) da turma é exigido do professor, algo de criatividade. Foi o que aconteceu hoje. E eu fui bem sucedida. (P2).

Interessante assinalar, que este sentimento de resignação encontrado parece estar associado ou, de certo modo, influenciando o processo de adoecimento. Resignar-se traz a conotação de não se ter mais esperança, não mobilizando a descobertas e realizações de estratégias de enfrentamento.

A insatisfação com a política de educação do governo esteve presente em alguns relatos, demonstrando o quanto os professores percebem-se desvalorizados pelo sistema educacional. O descaso do governo parece ser uma queixa que repercute diretamente nas condições de trabalho. Destaquem-se as precárias condições salariais da categoria em âmbito nacional. Só com a edição da Lei 11.738/2008 é que foi instituído um piso nacional para a categoria docente. Mesmo com esse advento legal só em 27 de fevereiro de 2011 é que o Superior Tribunal Federal declarou, após as Ações Diretas de Inconstitucionalidade interpostas pelos Estados de Rio Grande do Sul, Santa Catarina, Mato Grosso do Sul e Ceará, a constitucionalidade da Lei e que a mesma passa a viger a contar do dia 27 de abril de 2011. Esse panorama político presentifica-se na fala seguinte:

Em sala de aula foi tudo muito bem. Os alunos iniciaram um trabalho de literatura e estão super animados. Contudo, a presidente de sala pediu um momento para dar um aviso sobe um abaixo assinado para evitar as eleições de direção na escola (conquista dos professores depois de muita luta e também de alguns tapas a nós deferidos pela polícia). É um absurdo como o governo atual vem tentando fazer reinar até dentro da escola sua ditadura. É revoltante (P5).

Algumas VS referenciam a percepção dos professores quanto ao processo de desvalorização do trabalho docente, levando a um aumento nas dificuldades enfrentadas em seu dia-a-dia. Dentre os indícios dessa desvalorização pode-se citar, por exemplo, a desapropriação da função de professor enquanto mediador de conhecimentos, aliada ao desvio de função muitas vezes vivenciado no contexto docente.

Segundo Basso (1998), os professores são, por diversas vezes, levados a suprir exigências que não se encontram inseridas em sua formação, contribuindo para um sentimento de perda de identidade profissional, de constatação que ensinar às vezes não é o mais importante: “(...) Como professor acho que os alunos não mais nos têm como referência de conhecimento, respeito ou qualquer coisa”. (P4)

Gize-se a importância de o professor se identificar com a disciplina que ministra e com o magistério; essas
VS parecem indicar um sentimento de satisfação e identificação do professor com a sua atividade profissional, estando relacionado a uma maior atribuição de significado à atividade que realiza e uma melhor superação das dificuldades cotidianas. Interessante assinalar, que mesmo diante das dificuldades encontradas no dia a dia dos professores, a satisfação pela atividade docente ainda é uma marca importante na vivência dos mesmos: “(...) Adoro ensinar, e mais ainda perceber que eles compreenderam. Sinto-me super poderosa. (...) Sinto-me recompensada, pelas perguntas, pelas dúvidas, pelos pensamentos e pelos absurdos incrivelmente criativos que falaram hoje (...)" (P5).

Resta configurado o sentido do trabalho no contexto social; embora alterado pelas inúmeras metamorfoses por que passou nas últimas décadas, o trabalho ainda ocupa posição central no universo subjetivo, estando atrelado, em razão disso, a processos de adoecimento ou saúde às massas trabalhadoras. Nos termos de Morin (2001), "o trabalho representa um valor importante, exerce uma influência considerável sobre a motivação dos trabalhadores e também sobre sua satisfação e sua produtividade” (p. 8).

A análise dos eixos de sentido encontrados nos possibilitou uma visão ampla sobre o sentido de ser professor em uma escola pública no Estado da Paraíba, concorrendo para o desvelamento da atividade numa perspectiva vivencial, subjetiva, captada todas as vezes que mergulhamos no universo humano, que no trabalho vive, dialeticamente, o jogo entre o que lhe é prescrito e o que efetiva e organismicamente executa.

Por fim, frise-se que não foi ofertado um treinamento específico aos entrevistados em torno da Versão de Sentido (VS), entretanto Amatuzzi (2009) considera que a VS é uma atividade que vai se aprendendo a fazer. $\mathrm{Na}$ pesquisa em tela, percebeu-se uma preocupação daqueles em relatar objetivamente ocorrências do cotidiano escolar. Donde se conclui que a sequência dos relatos oportunizou o exercício da metodologia (VS), culminando com a produção da proposta encetada pelo autor.

\section{Considerações finais}

O sentido de ser professor da Língua Portuguesa na escola pública foi a janela que descortinou o horizonte da atividade docente em sua singularidade para os fins colimados pela presente pesquisa. O ensino da Língua Portuguesa, conforme estatuído na Lei 9394/1996 e nos Parâmetros Curriculares Nacionais, reveste-se de importância capital à leitura do mundo e à construção de outros saberes. Sua utilização evidencia o processo de subjetivação, expressando um conjunto de emoções e significados sociais, estéticos e éticos, que equaciona a conexão e o trânsito dos escolares no âmbito social.

Ancorados numa perspectiva fenomenológica capturou-se, na fala dos professores, aspectos positivos e 
negativos de suas vivências profissionais. Restou comprovado, conforme o fizeram outros estudos (Basso, 1998; Carlotto, 2002; Oliveira, 2004) que para a atividade docente advieram outras exigências e desafios, atinentes ao contexto social atual. Convivem, os professores, com um quadro de precarização das condições laborais, sucateamento da escola, baixo prestígio social de suas funções e salários indignos. Esta realidade tem gerado tensões e o surgimento de diversos estressores socioeconômicos e psicossociais, culminando em quadros de adoecimento docente, seja de natureza física, seja de natureza mental.

A partir da fala dos participantes foi possível perceber uma escola pública carente de novidades e desafios no planejamento e execução do processo ensino-aprendizagem. A esse fato soma-se a falta de eficientes políticas públicas que atendam às demandas da clientela que a procura, no sentido de minimizar o fosso na aprendizagem, determinado, inclusive, pela ausência do capital cultural exigido pela instituição escolar. Cristalinas também as dificuldades dos relacionamentos interpessoais entre professores e alunos, mediados pelo conteúdo escolar. De um lado, profissionais expostos às intempéries laborais discorridas anteriormente, a toda evidência; de outro, alunos que vivenciam realidades sociais adversas, submetidos a processos educativos tradicionais e não atrativos, ditos bancários, e um quadro social no qual os valores que balizavam e harmonizavam as relações sociais estão em descenso. Esse cenário tem suscitado a dúvida, a culpa, o estranhamento docente à profissão, a evasão profissional e escolar.

Não se podem olvidar os gigantescos desafios impostos à tarefa educativa, que se multiplicam num momento social extremamente complexo, nos quais as verdades parecem apenas temporárias, circunstanciais e tudo, sobretudo as profissões, tem que ser reinventado todos os dias. Discutiram-se também aspectos positivos da profissão docente, consubstanciados na satisfação com o exercício da docência, na gratificação dos professores quando percebem os alunos interagindo e crescendo no processo, no compromisso com a eficiência e eficácia de suas atuações, a percepção dos mesmos quanto à necessidade de inovação do processo educativo e, sobremaneira, a clareza quanto à aprendizagem como um processo inter-relacional que envolve alunos e professores por inteiro, na unidade de suas multiplicidades psicossociais. Em suma, o estudo propiciou um olhar em torno da experiência de ser professor da Língua Portuguesa, no contexto da escola pública. Seus achados apontam especificidades desse ramo do conhecimento, dado o lugar central que ocupa no universo acadêmico e social. As evidências capturadas na pesquisa sinalizam também que as especificidades do professor da Língua Portuguesa inserem-se no cenário laboral dos docentes em geral; um vivido marcado por diversos estressores, sem desconhecer os aspectos positivos que também lhes são afetos.
Conceituando a ideologia presente na educação, Freire argumenta: "ela me faz pensar nessas manhãs orvalhadas de nevoeiro em que mal vemos o perfil dos ciprestes como sombras que parecem muito manchas das sombras mesmas. Sabemos que há algo metido na penumbra, mas não o divisamos bem” (1996, p. 142). O presente estudo, além do intuito de ampliar as discussões em torno da experiência de ser professor da Língua Portuguesa em escola pública, almeja se constituir em candeia que possibilite melhor divisarmos o "perfil dos ciprestes" imersos no complexo cenário do fazer docente, que se ousou desvelar.

\section{Referências}

Amatuzzi, M. M. (2009). Psicologia fenomenológica: uma aproximação teórica humanista. Estudos de Psicologia (Campinas), 26,(1), 93-100.

Ariés, P. (1981). História Social da Criança e da Família. Rio de Janeiro: LTC.

Batista, J. B. V., Carlotto, M. S., Coutinho, A. S., Augusto, L. G. S. (2010). Prevalência da Síndrome de Burnout e fatores sociodemográficos e laborais em professores de escolas municipais da cidade de João Pessoa, PB. Revista Brasileira de Epidemiologia, 13, 502-512

Brasil (2000). Parâmetros Curriculares Nacionais Ensino Médio, Brasília: Ministério da Educação. Disponível em: <http:// portal.mec.gov.br/seb/arquivos/pdf/14_24.pdf>.

Basso, I. S. (1998). Significado e sentido do trabalho docente. Cad. CEDES (Campinas), 19(44), 19-32.

Bendassoli, P. F. \& Sobol, L. A. P. (2011) (Orgs). Clínicas do Trabalho: novas perspectivas para compreensão do trabalho na atualidade. São Paulo: Atlas.

Carlotto, M. S. (2002). A Síndrome de Burnout e o Trabalho Docente. Psicologia em Estudo (Maringá), 7(1), 21-29.

Feijoo, A. M. L. C. \& Magnan, V. C. (2012). Análise da Escolha Profissional: uma proposta fenomenológico-existencial. Psicologia: Ciência e Profissão, 32(2), 356-373.

Freire, P. (1996). Pedagogia da Autonomia: saberes necessários à prática educativa, São Paulo: Paz e Terra.

Frigotto, G. (2000). A educação e a formação técnico-profissional frente à globalização excludente e o desemprego estrutural. In L. H. Silva (Org.). Escola Cidadã no contexto da globalização (pp. 218-238). Petropólis: Vozes.

Gomes, A. R., Silva, M. J., Mourisco, S., Silva, S., Mota, A. \& Montenegro, N. (2006) Problemas e desafios no exercício da actividade docente: Um estudo sobre o stresse, "burnout", saúde física e satisfação profissional em professores do $3^{\circ}$ ciclo e ensino secundário. Revista Portuguesa de Educação (Braga),19, 67-93.

Gomes, A. R., Montenegro, N., Peixoto, A. M. B. C \& Peixoto, A. R. B. C. (2010) Stress ocupacional no ensino: um estudo com professores dos $3^{\circ}$ ciclos e ensino secundário. Psicologia $\&$ Sociedade, 22(3), 587-597. 
Holanda, A. (2006). Questões sobre pesquisa qualitativa e pesquisa fenomenológica. Análise Psicológica (Lisboa), 3(XXIV), 363-372.

Macêdo, S. M. (2000) Psicologia Clínica e aprendizagem significativa: relatando uma pesquisa fenomenológica colaborativa. Psicologia em Estudo (Maringá), 5(2), 49-76.

Mariano, M. S. S. \& Muniz, H. P. (2006). Trabalho docente e saúde: o caso dos professores da segunda fase do ensino fundamental. Estudos e Pesquisas em Psicologia (UERJ), 6(1), 76-88.

Morin, E. M. (2001). Os sentidos do Trabalho. Revista de Administração de Empresas (São Paulo), 41(3), 8-19.

Nogueira, C. M. M \& Nogueira, M. A. (2002). A sociologia da Educação de Pierre Bourdieu: limites e contribuições. Educação \& Sociedade, 23(78), 15-36.

Oliveira, D. A. (2004). A Reestruturação do Trabalho Docente: Precarização e Flexibilização. Educação \& Sociedade (Campinas), 25(89), 1127-1144.

Silva, T. T. (2010). Neoliberalismo, qualidade total e educação. Petrópolis: Vozes.

Vercelli. L. C. A. (2006). Versões de Sentido: um instrumento metodológico. Cadernos de Pós-Graduação - Educação (São Paulo), 5(1), 191-195

Sandra Souza da Silva - Doutora em Psicologia Social pela Universidade Federal do Rio Grande do Norte (UFRN), com estágio de doutoramento na Universidade Complutense de Madri. Atualmente é Professora e Supervisora de estágio clínico na Abordagem Centrada na Pessoa do Departamento de Psicologia da Universidade Federal da Paraíba (UFPB) e líder do Grupo de Pesquisa em Psicologia Fenomenológica Existencial. Endereço Institucional: Universidade Federal da Paraíba, Centro de Ciências Humanas Letras e Artes. Campus I. Cidade Universitária. CEP 58000.000 - João Pessoa/PB. E-mail: sandra.souza_psi@yahoo.com.br

Francisco Bento da Silva Filho - Mestre em Educação, Pedagogo, Psicólogo e pesquisador do Grupo de Pesquisa em Psicologia Fenomenológica Existencial do Departamento de Psicologia da UFPB. E-mail: otnebbpsi@gmail.com

Noely Cavalcanti de Menezes - Psicóloga e membro do Grupo de Pesquisa em Psicologia Fenomenológica Existencial do Departamento de Psicologia da Universidade Federal da Paraíba (UFPB). E-mail: noely_ncm@hotmail.com

Bruna Jucilene Carlos Gonzaga - Psicóloga e membro do Grupo de Pesquisa em Psicologia Fenomenológica Existencial do Departamento de Psicologia da Universidade Federal da Paraíba (UFPB). E-mail: brunajcg@gmail.com

Cicera Michelly de Sousa Teles - Psicóloga e membro do Grupo de Pesquisa em Psicologia Fenomenológica Existencial do Departamento de Psicologia da Universidade Federal da Paraíba (UFPB). E-mail: mmichelly1212@yahoo.com.br

Recebido em 30.04.2013 Primeira Decisão Editorial em 05.08.2013 Aceito em 17.06.2014 